Virginia Commonwealth University VCU Scholars Compass

2017

\title{
B-12(SCN)(12)(-): An Ultrastable Weakly Coordinating Dianion
}

\author{
Hong Fang \\ Virginia Commonwealth University \\ Puru Jena \\ Virginia Commonwealth University, pjena@vcu.edu
}

Follow this and additional works at: http://scholarscompass.vcu.edu/phys_pubs

Part of the Physics Commons

(C) 2017 American Chemical Society

\section{Downloaded from}

http://scholarscompass.vcu.edu/phys_pubs/209

This Article is brought to you for free and open access by the Dept. of Physics at VCU Scholars Compass. It has been accepted for inclusion in Physics Publications by an authorized administrator of VCU Scholars Compass. For more information, please contact libcompass@vcu.edu. 


\title{
$\mathrm{B}_{12}(\mathrm{SCN})_{12}^{-}$: An Ultrastable Weakly Coordinating Dianion
}

\author{
Hong Fang ${ }^{\circledR}$ and Puru Jena** \\ Department of Physics, Virginia Commonwealth University, 701 West Grace Street, Richmond, Virginia 23284, United States
}

\section{Supporting Information}

ABSTRACT: Stable dianions that are weakly coordinating with metal ions are not common. In this work, we show that the thiocyanate $\mathrm{SCN}^{-}$anion, known for its detoxification property of cyanide $\mathrm{CN}^{-}$and antidegradation property of perovskite solarcell materials, can also be used to produce a new set of weakly coordinating $\mathrm{B}_{12}(\mathrm{SCN})_{12}{ }^{-}$ dianion complexes which are potential candidates for the anionic part inside the electrolytes of metal-ion, especially the magnesium-ion-based, batteries.

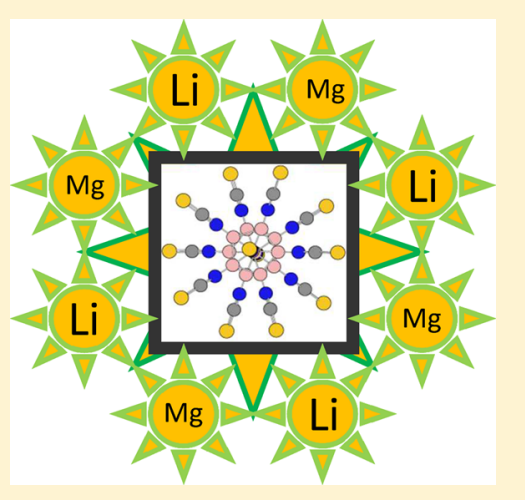

\section{INTRODUCTION}

Rechargeable metal-ion batteries have become an indispensable part of our modern life. They not only power portable devices such as cell phones and laptop computers to electric vehicles but also are essential for a clean energy future. Among the three major components of a battery-the anode, the cathode, and the electrolyte-the latter stands at the center as the supplier of metal ions which shuttle between the electrodes. Since magnesium batteries enjoy great cost-effective advantages compared to the currently used Li-ion batteries (LIBs), ${ }^{1-6}$ a great deal of effort has been made toward the discovery of promising electrolytes for multivalent metal batteries. ${ }^{7-9}$ In this context, complex metal borohydrides that have been considered for some time as hydrogen storage materials have found a niche application in making electrolytes. ${ }^{7,10}$ Recent experiments by Tutusaus et al. and Tang et al. ${ }^{4,11}$ demonstrated the exceptional properties of $\mathrm{CB}_{11} \mathrm{H}_{12}{ }^{-}$(monocarborane) as anionic components of electrolytes for magnesium battery and $\mathrm{Na}$-ion batteries, respectively. To find more candidates of the electrolyte salts for magnesium batteries, it would be important to develop stable dianions that are weakly bonded to metal cations. In a very recent work, Zhao et al. ${ }^{12}$ predicted the unusual stability of another dianion, $\mathrm{B}_{12}(\mathrm{CN})_{12}{ }^{2-}$, formed by replacing the $\mathrm{H}$ ligands in $\mathrm{B}_{12} \mathrm{H}_{12}{ }^{-}$by $\mathrm{CN}$ moieties. Using density functional theory, they calculated the binding energies of the first $\left(\Delta E_{1}\right)$ and second $\left(\Delta E_{2}\right)$ electrons. Known as electron affinities, these are defined, respectively, as

$$
\begin{aligned}
& \Delta E_{1}=E(\mathrm{X})-E\left(\mathrm{X}^{-}\right) \\
& \Delta E_{2}=E\left(\mathrm{X}^{-}\right)-E\left(\mathrm{X}^{2-}\right)
\end{aligned}
$$

where $\mathrm{X}$ is the moiety under investigations, such as $\mathrm{B}_{12}(\mathrm{CN})_{12}$. It was shown that the second electron in $\mathrm{B}_{12}(\mathrm{CN})_{12}{ }^{2-}$ is bound by $\Delta E_{2}=5.3 \mathrm{eV}$ which is about six times larger than the corresponding value of $0.9 \mathrm{eV}$ in the well-known closo-borane
$\mathrm{B}_{12} \mathrm{H}_{12}{ }^{-} \cdot \Delta E_{1}$ of $\mathrm{B}_{12}(\mathrm{CN})_{12}{ }^{2-}, 8.6 \mathrm{eV}$, is also much larger than the corresponding $4.6 \mathrm{eV}$ binding energy in $\mathrm{B}_{12} \mathrm{H}_{12}{ }^{2-}$. When one of the $\mathrm{B}$ atoms in the $\mathrm{B}_{12}(\mathrm{CN})_{12}$ is replaced by $\mathrm{C}, \Delta E_{1}$ of $\mathrm{CB}_{11}(\mathrm{CN})_{12}$ is $8.72 \mathrm{eV}$ which is also much larger than that of $\mathrm{CB}_{11} \mathrm{H}_{12}$. More importantly, the second electron in $\mathrm{CB}_{11}(\mathrm{CN})_{12}{ }^{2-}$ is bound by $1.07 \mathrm{eV}$, while the $\mathrm{CB}_{11} \mathrm{H}_{12}{ }^{2-}$ dianion is unstable compared to its monoanion state. It was further found that the binding energies of $\mathrm{Mg}^{2+}$ and $\mathrm{Li}^{+}$to $\mathrm{CB}_{11}(\mathrm{CN})_{12}{ }^{2-}$ and $\mathrm{CB}_{11}(\mathrm{CN})_{12}{ }^{-}$, respectively, are also significantly lower than those bound to $\mathrm{CB}_{11} \mathrm{H}_{12}{ }^{2-}$ and $\mathrm{CB}_{11} \mathrm{H}_{12}{ }^{-}$. All these properties indicate that $\mathrm{B}_{12}(\mathrm{CN})_{12}{ }^{2-}$ and $\mathrm{CB}_{11}(\mathrm{CN})_{12}^{-}$might serve as the anionic components of electrolytes inside metal-ion-based batteries. However, the cyanide ion $\mathrm{CN}^{-}$is highly toxic which will make it difficult to synthesize $\mathrm{B}_{12}(\mathrm{CN})_{12}{ }^{2-}$ in experiment.

In this paper, by making use of the accumulated knowledge in biological detoxification of $\mathrm{CN}^{-}$and materials design of perovskite solar cells, ${ }^{13,14}$ we report a new set of nontoxic ultrastable (di)anions with improved properties compared to $\mathrm{B}_{12}(\mathrm{CN})_{12}{ }^{2-}$ and $\mathrm{CB}_{11}(\mathrm{CN})_{12}{ }^{2-}$. We note that the giant stability of $\mathrm{B}_{12}(\mathrm{CN})_{12}{ }^{2-}$ is achieved by satisfying two electron counting rules, simultaneously. First, the $\mathrm{CN}$ moiety requires one electron to satisfy the octet shell closure rule and consequently has an electron affinity of $3.9 \mathrm{eV}$ that surpasses the electron affinity of any halogen atom. Thus, $\mathrm{CN}$ is a superhalogen. ${ }^{15}$ Second, the enhanced stability of $\mathrm{B}_{12}(\mathrm{CN})_{12}{ }^{2-}$ is due to the Wade-Mingos rule ${ }^{16-18}$ which requires $(n+1)$ pairs of electrons for its cage bonding. Here $n$ is the number of vertices in the $\mathrm{B}$ polyhedron. With $n=12, \mathrm{~B}_{12}(\mathrm{CN})_{12}{ }^{2-}$ requires 26 electrons to stabilize its icosahedra structure. It is because of the combined effect of the octet rule (that lends

Received: January 20, 2017

Revised: $\quad$ March 22, 2017

Published: March 28, 2017 
stability to the superhalogen $\mathrm{CN}$ ligand) and the WadeMingos rule (that lends stability to the icosahedral cage) that $\mathrm{B}_{12}(\mathrm{CN})_{12}{ }^{2-}$ enjoys its extraordinary stability.

\section{METHOD}

The calculations are carried out using the GAUSSIAN03 package. ${ }^{19}$ The hybrid density functional theory (DFT) with Becke three-parameter Lee-Yang-Parr (B3LYP) ${ }^{20,21}$ prescription for the exchange-correlation energy and the $6-31+G(d, p)$ basis set are used. The optimized ground states correspond to the structures with the minimum energy and without any imaginary frequency. Natural bond orbital (NBO) analysis is used to obtain the atomic charge state and the bond composition of the molecule. The intensity of the infraredactive mode is given as change of the dipole moment (in unit of $\mathrm{km} / \mathrm{mol}$ ) along the vibrational mode. The molecular dynamics simulations are conducted using an NVT ensemble with NoseHoover thermostat. A large $30 \times 30 \times 30 \AA$ cell is used to contain the studied anion. Simulations are conducted with normal precision in VASP ${ }^{22,23}$ and a tolerance of $1 \times 10^{-5} \mathrm{eV}$ for the SCF cycle without any symmetry constraint. van der Waals dispersion interactions are also considered using the DFT+D2 method. ${ }^{24,25}$ The time step is set to $2 \mathrm{fs}$. The solvation calculations are performed using the ground state of the gas-phase structures within the polarizable continuum model (PCM). In our study, the model is based on the work in refs 26 and 27. Such a solvation model has been tested for a number of solutes with different polarities using the $6-31+G(d)$ basis set at the DFT level. The agreement between the calculated solvation free energy and the experimental ones is reasonably good. ${ }^{26}$ All anions in the solvent remain stable without imaginary frequency. Our method of using the gas phase and the idealized solvation model to study the oxidative stability of the (di)anions and their interaction with metal cations is widely adopted in the field. ${ }^{8,9}$

\section{RESULTS AND DISCUSSION}

We replace the $\mathrm{CN}$ ligand in $\mathrm{B}_{12}(\mathrm{CN})_{12}{ }^{2-}$ with $\mathrm{SCN}$. Note that $\mathrm{SCN}$ also requires one extra electron to satisfy the octet rule. Indeed, the electron affinity of $\mathrm{SCN}, 3.5 \mathrm{eV}$, is very similar to that of Br. Thus, one can regard SCN as a pseudohalogen. It is known that thiocyanate, $\mathrm{SCN}^{-}$, is much less toxic and can be used as an antidote of $\mathrm{CN}^{-13}$. It has been shown experimentally that $\mathrm{SCN}^{-}$can be effectively removed from aqueous solutions by using low-cost natural waste biomass. ${ }^{28}$ Interestingly, $\mathrm{SCN}^{-}$ has recently been used to replace iodine in the organicinorganic hybrid perovskites to produce $\mathrm{CH}_{3} \mathrm{NH}_{3} \mathrm{PbI}(\mathrm{SCN})_{2}{ }^{14}$ making a leap forward in solving the long-standing problem of degradation of the perovskite solar-cell materials exposed to moisture. According to our own studies, ${ }^{29-31}$ the success of $\mathrm{SCN}^{-}$in improving the stability of the $\mathrm{CH}_{3} \mathrm{NH}_{3} \mathrm{PbI}_{3}$ organic hybrid perovskite solar cell is consistent with the role played by $\mathrm{Br}^{-}$in $\mathrm{CH}_{3} \mathrm{NH}_{3} \mathrm{PbI}_{2} \mathrm{Br}^{32}$ Due to the above merits of $\mathrm{SCN}^{-}$ compared to $\mathrm{CN}^{-}$, the production cost of metal salts made from $\mathrm{B}_{12}(\mathrm{CN})_{12}{ }^{2-}$ is expected to be greatly reduced.

In terms of the interaction of $\mathrm{B}_{12}(\mathrm{CN})_{12}{ }^{2-}$ or $\mathrm{CB}_{11}(\mathrm{CN})_{12}{ }^{-}$ with metal cations, the highly electronegative $\mathrm{CN}$ and the large volume work against each other. On one hand, larger volume means smaller charge density on the ion surface and hence weaker interaction with a point-charge metal ion. On the other hand, large negative charge concentrated on $\mathrm{CN}$ is likely to form a highly polarized bond with $\mathrm{Li}^{+} / \mathrm{Mg}^{2+}$. This may result in poor solubility of the salt in low-polarity solvents like ethers which, in the case of magnesium battery, are the only usable solvents so far. ${ }^{3,4}$ Thus, electrolytes based on $\mathrm{B}_{12}(\mathrm{SCN})_{12}{ }^{2-}$ and $\mathrm{CB}_{11}(\mathrm{SCN})_{12}{ }^{-}$may provide another advantage. With the smaller electron affinity of SCN compared to that of $\mathrm{CN}$, the bonding polarity between the anion and the metal cation is expected to be reduced. The increased volume of $\mathrm{B}_{12}(\mathrm{SCN})_{12}{ }^{2-}$ is likely to further reduce the magnitude of the interaction.

We first calculated the geometry of neutral and negative ions of $\mathrm{B}_{12}(\mathrm{SCN})_{12}$ and $\mathrm{CB}_{11}(\mathrm{SCN})_{12}$. The ground state of $\mathrm{B}_{12}(\mathrm{SCN})_{12}{ }^{2-}$ is found to be symmetric ( $C_{i}$ point group) with $\mathrm{N}$ ligated to $\mathrm{B}$ and each NCS branch pointing outward radially, as shown in Figure 1a. Its isomer where $S$ is ligated to a

C
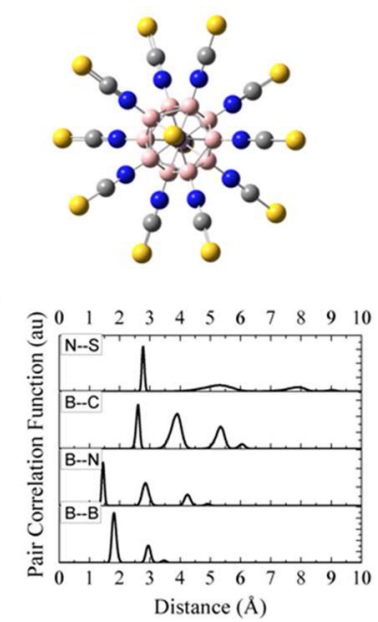

d

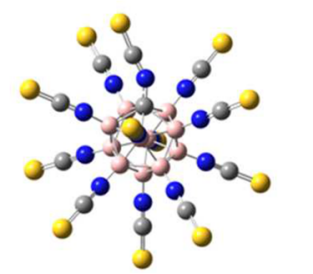

b

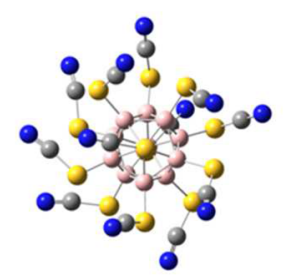

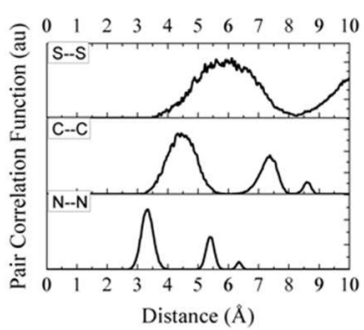

e

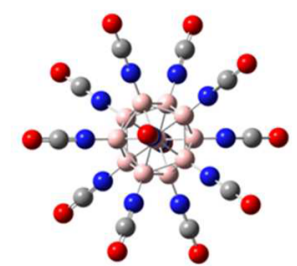

Figure 1. Optimized structures of (a) the ground state of $\mathrm{B}_{12}(\mathrm{SCN})_{12}{ }^{2-}$; (b) its isomer $\mathrm{B}_{12}(\mathrm{NCS})_{12}{ }^{2-}$; (d) the derivative $\mathrm{CB}_{11}(\mathrm{SCN})_{12}{ }^{-}$; and (e) the ground state of $\mathrm{B}_{12}(\mathrm{OCN})_{12}{ }^{-}$. Boron is in pink; nitrogen is in blue; carbon is in gray; sulfur is in yellow; and oxygen is in red. (c) Computed pair correlation functions (of B-B, B$\mathrm{N}, \mathrm{B}-\mathrm{C}, \mathrm{N}-\mathrm{S}, \mathrm{N}-\mathrm{N}, \mathrm{C}-\mathrm{C}$, and $\mathrm{S}-\mathrm{S}$ ) from the trajectory data of the molecular dynamics simulation at $500 \mathrm{~K}$ for 20 ps after the thermal equilibrium are reached.

B (see Figure $1 \mathrm{~b}$ ) is $13.8 \mathrm{eV}$ higher in energy and adopts a nonsymmetric configuration ( $C_{2}$ point group) with the bending angle $\mathrm{B}-\mathrm{S}-\mathrm{C}$ being $107^{\circ}$. NBO analysis reveals that the bending (larger than the $90^{\circ}$ with no sp mixing and smaller than $109^{\circ}$ with $\mathrm{sp}^{3}$ hybridization ${ }^{33}$ ) is due to the predominant $\mathrm{p}$ character (more than $75 \%$ contribution) in the $\mathrm{B}-\mathrm{S}$ bond with little s mixing. On the other hand, the straight $\mathrm{B}-\mathrm{N}-\mathrm{C}$ bond in the ground-state structure according to the $50: 50 \mathrm{sp}$ mixing of $\mathrm{N}$ is usually seen in the $\mathrm{N}$-ligated thiocyantes. ${ }^{33}$ Due to the high symmetry of the ground state, $\mathrm{B}_{12}(\mathrm{SCN})_{12}{ }^{2-}$ shows negligible dipole moment, similar to that of $\mathrm{B}_{12}(\mathrm{CN})_{12}{ }^{2-}$. This is advantageous because large clusters with big dipole moment may tend to dimerize. ${ }^{34}$

To study the dynamic motions inside $\mathrm{B}_{12}(\mathrm{SCN})_{12}{ }^{2-}$ under thermal excitation, we carried out molecular dynamics simulation (MDS) on the dianion at $500 \mathrm{~K}$ for $20 \mathrm{ps}$. Figure 
1c shows the calculated pair correlation functions (PCF) of B$\mathrm{B}, \mathrm{B}-\mathrm{N}, \mathrm{B}-\mathrm{C}$, and $\mathrm{N}-\mathrm{S}$ from the MDS trajectory data. The narrow peaks indicate a rigidity inside the structural skeleton and the SCN pseudohalogen. The main flexibility of the structure comes from the swaying motions of the $-\mathrm{N}-\mathrm{C}-\mathrm{S}$ branches upon thermal excitation, as demonstrated by the PCF in Figure 1c.

The calculated second and first electron affinity (see eqs 1 and 2) of $\mathrm{B}_{12}(\mathrm{SCN})_{12}{ }^{2-}$ are 3.28 and $5.65 \mathrm{eV}$, respectively. These values are compared to those of the other boron-cagebased anions in Table 1. They are large compared to those of

Table 1. First $\left(\Delta E_{1}\right)$ and Second $\left(\Delta E_{2}\right)$ Electron Affinity (Equation 1 and Equation 2) of $\mathrm{B}_{12}(\mathrm{SCN})_{12}{ }^{2-}$, $\mathrm{B}_{12}(\mathrm{OCN})_{12}{ }^{2-}$, and $\mathrm{CB}_{11}(\mathrm{SCN})_{12}{ }^{-}$Compared to Other Boron-Cage-Based Anions ${ }^{a}$

$\begin{array}{cccc} & \Delta E_{1}(\mathrm{eV}) & \Delta E_{2}(\mathrm{eV}) & \text { Oxidation Potential }(\mathrm{V}) \\ \mathrm{B}_{12} \mathrm{H}_{12} & 4.57 & 0.86 & 9.43\left(\mathrm{Mg}^{2+} / \mathrm{Mg}\right) \\ \mathrm{CB}_{11} \mathrm{H}_{12}{ }^{b} & 5.99 & -- & 5.54\left(\mathrm{Li}^{+} / \mathrm{Li}\right) ; 4.86\left(\mathrm{Mg}^{2+} / \mathrm{Mg}\right) \\ \mathrm{B}_{12}(\mathrm{SCN})_{12} & 5.65 & 3.28 & 10.34\left(\mathrm{Mg}^{2+} / \mathrm{Mg}\right) \\ \mathrm{B}_{12}(\mathrm{OCN})_{12} & 6.01 & 3.21 & 10.67\left(\mathrm{Mg}^{2+} / \mathrm{Mg}\right) \\ \mathrm{CB}_{11}(\mathrm{SCN})_{12} & 5.69 & -- & 5.16\left(\mathrm{Li}^{+} / \mathrm{Li}\right) ; 4.48\left(\mathrm{Mg}^{2+} / \mathrm{Mg}\right) \\ \mathrm{B}_{12}(\mathrm{CN})_{12}{ }^{c} & 8.56 & 5.28 & 15.95\left(\mathrm{Mg}^{2+} / \mathrm{Mg}\right) \\ \mathrm{CB}_{11}(\mathrm{CN})_{12}{ }^{c} & 8.72 & 1.07 & 13.16\left(\mathrm{Mg}^{2+} / \mathrm{Mg}\right)\end{array}$

${ }^{a}$ Values of the oxidation potential are calculated in THF solvent versus the standard electrode potential $\mathrm{Mg}^{2+} / \mathrm{Mg}$ of $2.05 \mathrm{~V}$ for the dianions and $\mathrm{Li}^{+} / \mathrm{Li}$ of $1.37 \mathrm{~V}$ for the monoanions. A standard hydrogen electrode value of $4.42 \mathrm{~V}$ is used. ${ }^{37}{ }^{b} \operatorname{Ref} 7 .{ }^{c} \operatorname{Ref} 12$.

the benchmark $\mathrm{B}_{12} \mathrm{H}_{12}{ }^{2-}$ and $\mathrm{CB}_{11} \mathrm{H}_{12}{ }^{-}$which have already been proven to have excellent oxidative stability. ${ }^{3,4}$ To the best of our knowledge, the value of $3.28 \mathrm{eV}$ binding energy of the second electron in $\mathrm{B}_{12}(\mathrm{SCN})_{12}{ }^{2-}$ is the second largest value reported so far, with $\mathrm{B}_{12}(\mathrm{CN})_{12}{ }^{2-12}$ being the most stable dianion known in the gas phase, and larger than those of perhalogenated dodecaborates $\mathrm{B}_{12} \mathrm{X}_{12}{ }^{2-}(\mathrm{X}=\text { halogen })^{35}$ and gigantic dimers $\mathrm{B}_{24} \mathrm{X}_{18}{ }^{2-}(\mathrm{X}=$ halogen $) .^{36}$

We further studied $\mathrm{CB}_{11}(\mathrm{SCN})_{12}{ }^{-}$and the isoelectroic $\mathrm{B}_{12}(\mathrm{OCN})_{12}{ }^{2-}$. The optimized ground states of these structures are given in Figure $1 \mathrm{~d}$ and $1 \mathrm{e}$, respectively. For $\mathrm{B}_{12}(\mathrm{OCN})_{12}{ }^{2-}$, the isomer with $\mathrm{O}$ linked to $\mathrm{B}$ is $15.3 \mathrm{eV}$ higher in energy than the ground state structure where $\mathrm{N}$ is linked to B. Both ions show excellent stability compared to the benchmark anions, as shown in Table 1. Different charge (from -2 to neutral) states of $\mathrm{B}_{12}(\mathrm{SCN})_{12}, \mathrm{CB}_{11}(\mathrm{SCN})_{12}$, and $\mathrm{B}_{12}(\mathrm{OCN})_{12}$ introduce minimal structural deformation, as shown in Table $\mathrm{S} 1$ of the SI, suggesting that the anion states are stabilized against the neutral state due to charge redistribution between the boron cage and the functional SCN ligand. Indeed, NBO analysis shows that, from the neutral state to the monoanion state, each boron atom and each SCN ligand receives about 0.02 and 0.08 electrons, respectively; from the monoanion to the dianion, each boron and each SCN obtain another 0.03 and 0.07 electrons, respectively. These values are similar to the case of $\mathrm{B}_{12}(\mathrm{CN})_{12}$, ${ }^{12}$ suggesting that the electron-drawing ability of SCN is also large compared to the boron cage.

To calculate the interaction between $\mathrm{B}_{12}(\mathrm{SCN})_{12}{ }^{2-}$ and its derivatives with metal ions, we first determined the groundstate structures of the corresponding salts, including $\left[\mathrm{LiB}_{12}(\mathrm{SCN})_{12}\right]^{-}, \quad \mathrm{Li}_{2} \mathrm{~B}_{12}(\mathrm{SCN})_{12}, \quad \mathrm{LiCB}_{11}(\mathrm{SCN})_{12}$, and $\mathrm{MgB}_{12}(\mathrm{SCN})_{12}$. These are shown in Figure $\mathrm{S} 1$ of the SI. The bonding pattern between the anion and the metal cation is the same as that involving $\mathrm{B}_{12}(\mathrm{CN})_{12}{ }^{2-}$ (see Figure S1e of SI and ref 12 ). Each metal cation is held by three ligand branches. We then calculate the energy cost, $E_{\mathrm{b}}$, to dissociate the metal ion from the anion by using the equation

$$
E_{\mathrm{b}}=E_{\text {dianion }}+E_{\mathrm{mc}}-\left(E_{\text {salt }}-E_{\mathrm{d}}\right)
$$

where $E_{\mathrm{d}}$ is the energy cost due to the distortion of the dianion caused by binding with the metal ion; $E_{\text {dianion }}$ is the ground-state energy of the dianion; $E_{\mathrm{mc}}$ is the energy of the metal cation; and $E_{\text {salt }}$ is the ground-state energy of the salt. We rewrite eq 3 as

$$
\begin{aligned}
E_{\mathrm{b}} & =E_{\text {dissociation }}+E_{\mathrm{d}}=\left(E_{\text {dianion }}+E_{\mathrm{d}}\right)+E_{\mathrm{mc}}-E_{\text {salt }} \\
& =E_{\text {distort }}+E_{\mathrm{mc}}-E_{\text {salt }}
\end{aligned}
$$

Here $E_{\text {dissociation }}$ is the dissociation energy defined as the sum of the energy of the anion and the metal ion minus the energy of the corresponding salt. $E_{\text {distort }}$ is the energy of the dianion at the distorted configuration (caused by binding to the metal cation). The calculated $E_{\mathrm{b}}$ for the studied salts are given in Table 2. It is clear that $\mathrm{B}_{12}(\mathrm{SCN})_{12}{ }^{2-}$ and $\mathrm{CB}_{11}(\mathrm{SCN})_{12}{ }^{-}$salts require the least energy to dissociate into $\mathrm{Li}^{+}$or $\mathrm{Mg}^{2+}$, especially compared to the benchmark $\mathrm{B}_{12} \mathrm{H}_{12}{ }^{2-}$ and $\mathrm{CB}_{11} \mathrm{H}_{12}{ }^{-}$.

Table 2. Calculated Energy $E_{\mathrm{b}}(\mathrm{eV})$ to Dissociate the Metal Ion $\left(\mathrm{Li}^{+} / \mathrm{Mg}^{2+}\right)$ from the Studied Salts ${ }^{a}$

\begin{tabular}{llllll}
\multicolumn{1}{c}{ Li salt } & $\begin{array}{c}\mathrm{Li}^{+} \\
(\text {first })\end{array}$ & $\begin{array}{c}\mathrm{Li}^{+} \\
\text {(second) }\end{array}$ & \multicolumn{1}{c}{$\mathrm{Mg}$ salt } & $\mathrm{Mg}^{2+}$ & $\begin{array}{c}\text { THF } \\
\mathrm{Li}_{2} \mathrm{~B}_{12} \mathrm{H}_{12}\end{array}$ \\
$5.91^{b}$ & $9.03^{b}$ & $\mathrm{MgB}_{12} \mathrm{H}_{12}$ & 21.19 & 1.73 \\
$\mathrm{LiCB}_{11} \mathrm{H}_{12}$ & 5.40 & -- & $\mathrm{Mg}\left(\mathrm{CB}_{11} \mathrm{H}_{12}\right)_{2}$ & 20.38 & 1.27 \\
$\mathrm{Li}_{2} \mathrm{~B}_{12}(\mathrm{CN})_{12}$ & 5.16 & 7.44 & $\mathrm{MgCB}_{11}(\mathrm{CN})_{12}$ & 19.70 & 1.07 \\
$\mathrm{Li}_{2} \mathrm{~B}_{12}(\mathrm{SCN})_{12}$ & 5.07 & 6.89 & $\mathrm{MgB}_{12}(\mathrm{CN})_{12}$ & 18.29 & 0.51 \\
$\mathrm{Li}_{2} \mathrm{CB}_{11}(\mathrm{CN})_{12}$ & $4.67^{b}$ & 7.65 & $\mathrm{MgB}_{12}(\mathrm{SCN})_{12}$ & 18.37 & 0.39 \\
$\mathrm{LiCB}_{11}(\mathrm{SCN})_{12}$ & $4.40^{b}$ & -- & & &
\end{tabular}

${ }^{a}$ The energy to dissociate $\mathrm{Mg}^{2+}$ from the studied dianions in the solvent THF is also given. ${ }^{b}$ Values of $E_{\text {dissociation }}$ in eq 4.

We further considered the properties of the studied anions in solution. For magnesium battery, the only known solvent that is compatible with $\mathrm{Mg}$ is ether. ${ }^{3,4}$ In our calculations we therefore adopt tetrahydrofuran (THF, $\mathrm{C}_{4} \mathrm{H}_{8} \mathrm{O}, \varepsilon=7.52$ ) which has been used in the experiments as the solvent (see the Method section). ${ }^{3,4}$ The computed oxidation potentials of the anions in THF are given in Table 1 . For the dianions, the values are reported versus the $\mathrm{Mg}^{2+} / \mathrm{Mg}$ standard electrode potential of $(4.42-2.372 \approx) 2.05 \mathrm{~V} .^{38}$ The reported values for the monoanions are converted to $\mathrm{Li}^{+} / \mathrm{Li}(1.37 \mathrm{~V})$ scale. The oxidation potentials of the dianions increase significantly due to the charge separation effect in the solvent. The trend of these potentials is the same as that of the gas phase- $-\mathrm{B}_{12}(\mathrm{SCN})_{12}{ }^{2-}$ and its derivatives show higher oxidative stability compared to the benchmark anions. We want to emphasize that, although it has been shown that DFT calculations with B3LYP/6$31+G(d, p)$ often result in systematic discrepancy for the reproduction of experimental redox potentials of anions, such a method can still reproduce the correct trends of the oxidative stability of anions. ${ }^{39-42}$ Rather than trying to match the experimental values, our choice of method (see the Method section) here is to use the same combination of exchangecorrelation functional (B3LYP) and the basis set (6-31+G$(\mathrm{d}, \mathrm{p}))$ as that in ref 12 so that the stability trends of the clusters can be drawn from the calculations with and without the solvation model. 
Since ethers are solvents with low polarity, it is essential to make the bonding between the $\mathrm{Mg}$ ion and the anion in a salt less ionic to enhance its solubility. One way to evaluate the bond polarization together with the bond strength is to study the calculated infrared (IR) vibrations. The vibrational frequency is a direct measurement of the force constant of the bond. The change of the dipole moment along a given vibrational mode is directly proportional to the intensity reflected in the IR spectrum. It is noted that any vibration involving the relative motion of the metal ion against the anion should change the dipole moment of the molecule and, therefore, should be IR active. The modes with the metal ion vibrating against a static anion are the least energetic ones among the modes with measurable IR intensities, given the high symmetry of the ground states of the studied anions and their rigid skeleton as discussed previously.

In Figure 2 we compare the frequency as well as the intensities of these calculated IR modes in $\mathrm{MgB}_{12} \mathrm{H}_{12}$,

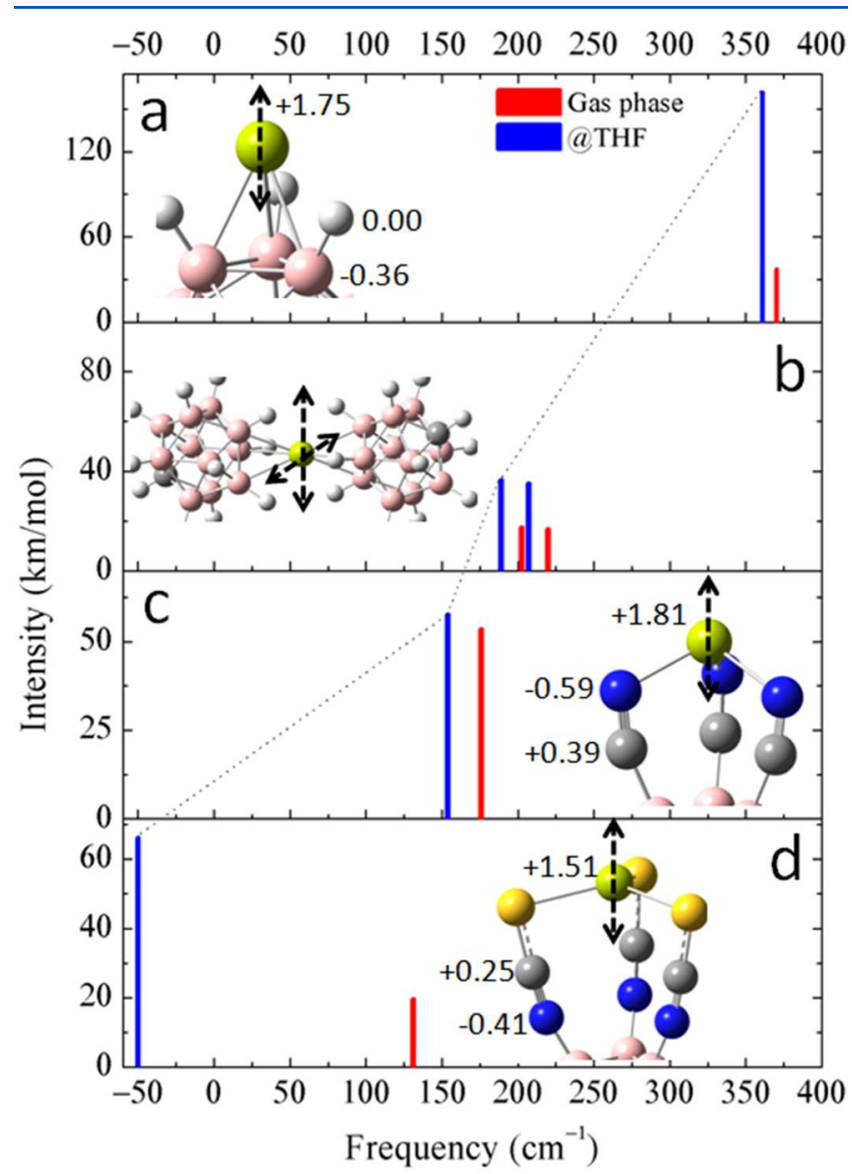

Figure 2. IR mode related to the dissociation of the $\mathrm{Mg}$ ion from the anion in (a) $\mathrm{MgB}_{12} \mathrm{H}_{12}$, (b) $\mathrm{Mg}\left(\mathrm{CB}_{11} \mathrm{H}_{12}\right)_{2}$, (c) $\mathrm{MgB}_{12}(\mathrm{CN})_{12}$, and (d) $\mathrm{MgB}_{12}(\mathrm{SCN})_{12}$. The dotted line is to guide the eye. In each case, the vibration in the gas phase is in red, and the vibration in the THF solvent is in red. The numbers show the charge states of the atoms from the $\mathrm{NBO}$ analysis. $\mathrm{Mg}$ is in green-yellow, $\mathrm{H}$ is in white, $\mathrm{B}$ is in pink, $\mathrm{N}$ is in blue, $\mathrm{C}$ is in gray, and $\mathrm{S}$ is in yellow.

$\operatorname{Mg}\left(\mathrm{CB}_{11} \mathrm{H}_{12}\right)_{2}, \mathrm{MgB}_{12}(\mathrm{CN})_{12}$, and $\operatorname{MgB}_{12}(\mathrm{SCN})_{12}$. In each case, we give the longitudinal mode of the $\mathrm{Mg}$ ion vibrating against the anion. From $\mathrm{MgB}_{12} \mathrm{H}_{12}$ to $\mathrm{MgB}_{12}(\mathrm{SCN})_{12}$, the mode frequency decreases, suggesting weaker bond strength. Compared to $\mathrm{MgB}_{12} \mathrm{H}_{12}, \mathrm{Mg}\left(\mathrm{CB}_{11} \mathrm{H}_{12}\right)_{2}$ already shows significantly lower bond strength (see Figure $2 \mathrm{a}$ and $2 \mathrm{~b}$ ) between the $\mathrm{Mg}$ ion and the anion. The IR mode of $\mathrm{MgB}_{12}(\mathrm{SCN})_{12}$ shows much lower intensity than the other three salts in Figure $2 c$, indicating low polarity of the bond, while $\mathrm{MgB}_{12}(\mathrm{CN})_{12}$ shows higher intensity (Figure 2d) and therefore higher bond polarity due to the concentration of negative charge on $\mathrm{N}$ (as discussed at the beginning of this paper). This trend is consistent with the atomic charge states obtained by the NBO analysis, where the $\mathrm{Mg}$ ion has the smallest charge of $+1.51 e$ bonded to three $\mathrm{S}$ atoms with $-0.20 e$ in $\mathrm{MgB}_{12}(\mathrm{SCN})_{12}$ (Figure 2c), while in $\mathrm{MgB}_{12}(\mathrm{CN})_{12}, \mathrm{Mg}$ with charge $+1.81 e$ is bonded to three $\mathrm{N}$ atoms, each carrying $-0.59 e$ (Figure 2d). The ground states of $\mathrm{LiCB}_{11} \mathrm{H}_{12}, \mathrm{LiCB}_{11}(\mathrm{SCN})_{12}$, $\left[\mathrm{MgCB}_{11} \mathrm{H}_{12}\right]^{+}$, and $\mathrm{Mg}\left(\mathrm{CB}_{11} \mathrm{H}_{12}\right)_{2}$ are given in Figure $\mathrm{S} 2$ of SI. In the presence of solvent, IR intensities increase due to the enhancement of the polarized vibration of $\mathrm{Mg}^{2+}$ against the dianion. The bond strength is greatly weakened in each case. Interestingly, the very IR mode relevant to the dissociation of $\mathrm{Mg}^{2+}$ with $\mathrm{B}_{12}(\mathrm{SCN})_{12}{ }^{2-}$ becomes unstable in the solvent, as indicated by its imaginary frequency. This suggests that $\mathrm{MgB}_{12}(\mathrm{SCN})_{12}$ would readily dissolve in THF compared to the other studied compounds. The trends of the results are consistent with the calculated dissociation energy in the solvent, as given in Table 2 .

\section{CONCLUSIONS}

In conclusion, we show that $\mathrm{SCN}$, which is used for detoxification of $\mathrm{CN}$ and for moisture resistance of the perovskite solar cells, can also be used to produce a new set of weakly coordinating anions. Compared to $\mathrm{B}_{12}(\mathrm{CN})_{12}{ }^{2-}$, $\mathrm{B}_{12}(\mathrm{SCN})_{12}{ }^{2-}$ displays improved properties, while maintaining high stability. Because of the unusual stability and its much weaker interaction with the metal ions compared to those of the benchmark negative ions $\mathrm{CB}_{11} \mathrm{H}_{12}{ }^{-}, \mathrm{B}_{12}(\mathrm{SCN})_{12}{ }^{2-}$ and its derivatives $\mathrm{CB}_{11}(\mathrm{SCN})_{12}{ }^{-}$are promising weakly coordinating anions which may have applications in the electrolytes of metalion-based batteries. As mentioned before, electrolyte is a complicated system having different components and interactions between them. We hope that our theoretical work will guide experiments in the discovery of the new electrolytes and study their effectiveness in comparison to those being currently used in commercial batteries.

\section{ASSOCIATED CONTENT}

\section{Supporting Information}

The Supporting Information is available free of charge on the ACS Publications website at DOI: 10.1021/acs.jpcc.7b00669.

Optimized bond lengths of the studied (di)anions; calculated ground states of $\mathrm{LiCB}_{11} \mathrm{H}_{12},\left[\mathrm{MgCB}_{11} \mathrm{H}_{12}\right]^{+}$, and $\mathrm{Mg}\left(\mathrm{CB}_{11} \mathrm{H}_{12}\right)_{2}$; calculated ground states of $\left[\mathrm{LiB}_{12}(\mathrm{SCN})_{12}\right]^{-}, \quad \mathrm{Li}_{2} \mathrm{~B}_{12}(\mathrm{SCN})_{12}, \quad \operatorname{LiCB}_{11}(\mathrm{SCN})_{12}$, $\mathrm{MgB}_{12}(\mathrm{SCN})_{12}$, and $\mathrm{MgB}_{12}(\mathrm{CN})_{12}(\mathrm{PDF})$

\section{AUTHOR INFORMATION}

\section{Corresponding Author}

*E-mail: pjena@vcu.edu.

ORCID $\odot$

Hong Fang: 0000-0002-0968-8687

Puru Jena: 0000-0002-2316-859X

Notes

The authors declare no competing financial interest. 


\section{ACKNOWLEDGMENTS}

This work is supported in part by the U.S. Department of Energy, Office of Basic Energy Sciences, Division of Materials Sciences and Engineering under Award \# DE-FG0296ER45579. Resources of the National Energy Research Scientific Computing Center supported by the Office of Science of the U.S. Department of Energy under Contract No. DE-AC02-05CH11231.

\section{REFERENCES}

(1) Bucur, C. B.; Gregory, T.; Oliver, A. G.; Muldoon, J. Confession of a Magnesium Battery. J. Phys. Chem. Lett. 2015, 6, 3578-3591.

(2) Younesi, R.; Veith, G. M.; Johansson, P.; Edström, K.; Vegge, T. Lithium Salts for Advanced Lithium Batteries: $\mathrm{Li}-$ metal, $\mathrm{Li}-\mathrm{O}_{2}$, and Li-S. Energy Environ. Sci. 2015, 8, 1905-1922.

(3) Carter, T. J.; Mohtadi, R.; Arthur, T. S.; Mizuno, F.; Zhang, R.; Shirai, S.; Kampf, J. W. Boron Clusters as Highly Stable MagnesiumBattery Electrolytes. Angew. Chem. 2014, 126, 3237-3241.

(4) Tutusaus, O.; Mohtadi, R.; Arthur, T. S.; Mizuno, F.; Nelson, E. G.; Sevryugina, Y. V. An Efficient Halogen-Free Electrolyte for Use in Rechargeable Magnesium Batteries. Angew. Chem., Int. Ed. 2015, 54, 7900-7904.

(5) Muldoon, J.; Bucur, C. B.; Oliver, A. G.; Sugimoto, T.; Matsui, M.; Kim, H. S.; Allred, G. D.; Zajicek, J.; Kotani, Y. Electrolyte Roadblocks to a Magnesium Rechargeable Battery. Energy Environ. Sci. 2012, 5, 5941-5950.

(6) Mohtadi, R.; Mizuno, F. Magnesium Batteries: Current State of the Art, Issues and Future Perspectives. Beilstein J. Nanotechnol. 2014, 5, 1291-1311.

(7) Giri, S.; Behera, S.; Jena, P. Superhalogens as Building Blocks of Halogen-Free Electrolytes in Lithium-Ion Batteries. Angew. Chem., Int. Ed. 2014, 53, 13916-13919.

(8) Borodin, O.; Behl, W.; Jow, T. R. Oxidative Stability and Initial Decomposition Reactions of Carbonate, Sulfone, and Alkyl PhosphateBased Electrolytes. J. Phys. Chem. C 2013, 117, 8661-8682.

(9) Borodin, O.; Olguin, M.; Spear, C. E.; Leiter, K. W.; Knap, J. Towards High Throughput Screening of Electrochemical Stability of Battery. Nanotechnology 2015, 26, 354003-354018.

(10) Unemoto, A.; Matsuo, M.; Orimo, S. Complex Hydrides for Electrochemical Energy Storage. Adv. Funct. Mater. 2014, 24, $2267-$ 2279.

(11) Tang, W. S.; Unemoto, A.; Zhou, W.; Stavila, V.; Matsuo, M.; Wu, H.; Orimo, S.; Udovic, T. J. Unparalleled Lithium and Sodium Superionic Conduction in Solid Electrolytes with Large Monovalent Cage-like Anions. Energy Environ. Sci. 2015, 8, 3637-3645.

(12) Zhao, H.; Zhou, J.; Jena, P. Stability of $\mathrm{B}_{12}(\mathrm{CN})_{12}{ }^{2-}$ : Implications for Lithium and Magnesium Ion Batteries. Angew. Chem., Int. Ed. 2016, 55, 1.

(13) Chaudhary, M.; Gupta, R. Cyanide Detoxifying Enzyme. Curr. Biotechnol. 2012, 1, 327-335.

(14) Jiang, Q.; Rebollar, D.; Gong, J.; Piacentino, E. L.; Zheng, C.; $\mathrm{Xu}, \mathrm{T}$. Pseudohalide-Induced Moisture Tolerance in Perovskite $\mathrm{CH}_{3} \mathrm{NH}_{3} \mathrm{~Pb}(\mathrm{SCN})_{2} \mathrm{I}$ Thin Films. Angew. Chem., Int. Ed. 2015, 54, 7617-7620.

(15) Gutsev, G. L.; Boldyrev, A. I. DVM-X $\alpha$ Calculations on the Ionization Potentials of $\mathrm{MX}_{\mathrm{k}+1}$ - Complex Anions and the Electron Affinities of $\mathrm{MX}_{\mathrm{k}+1}$ "Superhalogens. Chem. Phys. 1981, 56, 277-283.

(16) Wade, K. The Structural Significance of the Number of Skeletal Bonding Electron-pairs in Carboranes, the Higher Boranes and Borane Anions, and Various Transition-metal Carbonyl Cluster Compounds. J. Chem. Soc. D 1971, 792-793.

(17) Wade, K. Structural and Bonding Patterns in Cluster Chemistry. Adv. Inorg. Chem. Radiochem. 1976, 18, 1-66.

(18) Mingos, D. M. P. Polyhedral Skeletal Electron Pair Approach. Acc. Chem. Res. 1984, 17, 311-319.

(19) Frisch, M. J. Gaussian 03, revision B. 03; Gaussian, Inc.: Wallingford, CT, 2003.
(20) Becke, A. Density-functional Thermochemistry. III. The Role of Exact Exchange. J. Chem. Phys. 1993, 98, 5648-5652.

(21) Lee, C.; Yang, W.; Parr, R. G. Development of the Colle-Salvetti Correlation-energy Formula into a Functional of the Electron Density. Phys. Rev. B: Condens. Matter Mater. Phys. 1988, 37, 785-788.

(22) Kresse, G.; Furthmueller, J. Efficiency of Ab-initio Total Energy Calculations for Metals and Semiconductors Using a Plane-wave Basis Set. Comput. Mater. Sci. 1996, 6, 15-50.

(23) Kresse, G.; Furthmueller, J. Efficient Iterative Schemes for Ab Initio Total-energy Calculations Using a Plane-wave Basis Set. Phys. Rev. B: Condens. Matter Mater. Phys. 1996, 54, 11169-11186.

(24) Grimme, S. Semiempirical GGA-type Density Functional Constructed with a Long-range Dispersion Correction. J. Comput. Chem. 2006, 27, 1787.

(25) Fang, H.; Dove, M.; Refson, K. Ag-Ag Dispersive Interaction and Physical Properties of $\mathrm{Ag}_{3} \mathrm{Co}(\mathrm{CN})_{6}$. Phys. Rev. B: Condens. Matter Mater. Phys. 2014, 90, 054302.

(26) Cossi, M.; Scalmani, G.; Rega, N.; Barone, V. New Developments in the Polarizable Continuum Model for Quantum Mechanical and Classical Calculations on Molecules in Solution. J. Chem. Phys. 2002, 117, 43-54.

(27) Mennucci, B.; Tomasi, J. Continuum Solvation Models: A New Approach to the Problem of Solute's Charge Distribution and Cavity Boundaries. J. Chem. Phys. 1997, 106, 5151-5158.

(28) Thakur, R. Y.; Patil, Y. B. Management of Thiocyanate Pollution Using a Novel Low Cost Natural Waste Biomass. South Asian J. Management Res. 2009, 1, 85-95.

(29) Fang, H.; Jena, P. Super-ion Inspired Colorful Hybrid Perovskite Solar Cells. J. Mater. Chem. A 2016, 4, 4728-4737.

(30) Fang, H.; Jena, P. Molecular Origin of Properties of OrganicInorganic Hybrid Perovskites: The Big Picture from Small Clusters. J. Phys. Chem. Lett. 2016, 7, 1596-1603.

(31) Yao, Q.; Fang, H.; Deng, K.; Kan, E.; Jena, P. Super-halogens as Building Blocks of Two-dimensional Organic-inorganic Hybrid Perovskites for Optoelectronics Applications. Nanoscale 2016, 8, 17836-17842.

(32) Noh, J. H.; Im, S. H.; Heo, J. H.; Mandal, T. N.; Seok, S. I. Chemical Management for Colorful, Efficient, and Stable InorganicOrganic Hybrid Nanostructured Solar Cells. Nano Lett. 2013, 13, 1764-1769.

(33) Buda, C.; Kazi, A. B.; Dinescu, A.; Cundari, T. R. Stability Studies of Transition-Metal Linkage Isomers Using Quantum Mechanical Methods: Groups 11 and 12 Transition Metals. J. Chem. Inf. Model. 2005, 45, 965-970.

(34) Warneke, J.; Dülcks, T.; Knapp, C.; Gabel, D. Collision-induced Gas-phase Reactions of PerhalogenatedCloso-dodecaborate Clusters a Comparative Study. Phys. Chem. Chem. Phys. 2011, 13, 5712-5721.

(35) Boeré, R. T.; Kacprzak, S.; keßler, M.; Knapp, C.; Riebau, R.; Riedel, S.; Roemmele, T. L.; Rühle, M.; Scherer, H.; Weber, S. Oxidation of closo- $\left[\mathrm{B}_{12} \mathrm{Cl}_{12}\right]^{2-}$ to the radical anion $\left[\mathrm{B}_{12} \mathrm{Cl}_{12}\right]^{-}$and to neutral $\mathrm{B}_{12} \mathrm{Cl}_{12}$. Angew. Chem., Int. Ed. 2011, 50, 549-552.

(36) Krossing, I.; Raabe, I. Noncoordinating Anions - Fact or Fiction? A Survey of Likely Candidates. Angew. Chem., Int. Ed. 2004, 43, 2066-2090.

(37) Trasatti, S. The Absolute Electrode Potential: an Explanatory Note. Pure Appl. Chem. 1986, 58, 955-966.

(38) Petr, V. Electrochemical Series, Handbook of chemistry and physics, 92nd ed.; 2011.

(39) Ue, M.; Murakami, A.; Nakamura, S. Anodic Stability of Several Anions Examined by $\mathrm{Ab}$ Initio Molecular Orbital and Density Functional Theories. J. Electrochem. Soc. 2002, 149, A1572-A1577.

(40) Fu, Y.; Liu, L.; Yu, H. Z.; Wang, Y. M.; Guo, Q. X. QuantumChemical Predictions of Absolute Standard Redox Potentials of Diverse Organic Molecules and Free Radicals in Acetonitrile. J. Am. Chem. Soc. 2005, 127, 7227-7234.

(41) Wang, R. L.; Buhrmester, C.; Dahn, J. R. Calculations of Oxidation Potentials of Redox Shuttle Additives for Li-Ion Cells. J. Electrochem. Soc. 2006, 153, A445-A449. 
(42) Johansson, P. Intrinsic Anion Oxidation Potentials. J. Phys. Chem. A 2007, 111, 1378-1379. 